KEMAS 13 (3) (2018) 417-422
Jurnal Kesehatan Masyarakat

\title{
USAGE OF FRUIT-INFUSED WATER FOR PREVENTION OF DEHYDRATION DUE TO ENDURANCE EXERCISE
}

\author{
Mohammad Arif Ali ${ }^{1 凶}$, Setya Rahayu ${ }^{1}$, Nanang Indardi ${ }^{1}$, Gustiana Mega Anggita ${ }^{1}$, Fatona \\ Suraya $^{1}$, Tri Rustiadi ${ }^{2}$, Anggit Wicaksono ${ }^{3}$, Yu-Shiuan Chen ${ }^{4}$, Yun-Zhen Chang ${ }^{5}$ \\ ${ }^{1}$ Department of Sports Sciences, Faculty of Sports Sciences, Universitas Negeri Semarang, Indonesia \\ ${ }^{2}$ Department of Physical Education, Faculty of Sports Sciences, Universitas Negeri Semarang, Indonesia \\ ${ }^{3}$ Department of Sports Coaching Education, Faculty of Sports Sciences, Universitas Negeri Semarang, \\ Indonesia \\ ${ }^{4}$ New Taipei City Hospital Burn Rehabilitation \& Post-Acute Care Center, Taiwan (R.O.C) \\ ${ }^{5}$ Yu Da University of Science and Technology, Taiwan (R.O.C)
}

\section{Article Info}

Article History:

Submitted January 2018 Accepted February 2018

Published March 2018

\section{Keywords:}

Exercise, Fluid Replace-

ment, Fruit-Infused Water

\section{DOI}

https://doi.org/10.15294/

kemas.v13i3.12977

\begin{abstract}
This study aimed to extend previous investigation regarding its beneficial effects on changes of blood glucose. This experimental research was conducted from 06:00-12:00. Twenty-four young men (age 19-20 y.o.) were divided into three groups, Fasting-Exercise-Only (FEO), Fasting-Exercise-Water (FEW), and Fasting-Exercise with Fruit-Infused Water (FEF). Subjects underwent fasting for $12 \mathrm{~h}$ before the experimental day. The data of body weight $(\mathrm{Kg})$ and macroscopic urine color were collected before and after exercise. Body weight in all experimental groups were decreased by $1 \%$ during endurance exercise. There were no differences in decrease of body weight between FEF and FEW groups compared to FEO group ( $\mathrm{p}>.05$ ). The change in urine color was significantly different between pre-exercise and post-exercise data $(\mathrm{p}<.05)$. The darkest urine color was observed in FEO group (4.75), followed by FEW group (4.25), while FEF group (3.63) did not reach dehydration level. In conclusion, fruit-infused water is suggested to be drink as a choice for fluid intake during exercise.
\end{abstract}

\section{Introduction}

Exercise has many beneficial effects on the body for all ages as long as it is done correctly, properly, systematically, and regularly (exercise should be adjusted to physiological function). Exercise is able to improve the overall health status of an individual (Hagen, K.B. et al, 2012; Locks, R.R. et al, 2012). Yet, exercise is also known as physical stress which is able to affect physiological processes inside the body. One of consequences of exercise is dehydration (loss of water) which is caused by long- duration exercise (typically aerobic exercise) such as jogging, cycling, swimming, hiking, etc. Indicators of dehydration are thirstiness, dizziness, exhaustion, muscle spasm, loss of body weight, change of urine color, and vomiting (Sawka, M.N., 2007; Simpson, M.R. and Howard, T., 2011).

Dehydration causes loss of mineral and electrolytes (potassium, sodium, chloride etc.), increase of body temperature, change in cardiovascular system, disturbance in nerve system, and eventually it will impair exercise

\footnotetext{
Correspondence Address:

Department of Sports Sciences, Faculty of Sports Sciences, Universitas Negeri Semarang.

Email : hiarifalikhan@mail.unnes.ac.id 
performance (Murray, B., 2007). Previous studies reported that $2 \%$ loss of body weight could impair performance for about $7 \%-29 \%$ (Goulet, E.D.B., 2012). Dehydration during exercise occurred in heat condition (Hackney, K.J. et al, 2012).

Techniques or substances which can be used in order to maintain exercise performance called as ergogenic aids. It is classified into nutrition (carbohydrate loading, drugs such as usage of anabolic-androgenic steroid), physiological condition, psychological condition, and technique. As part of ergogenic aids, the right nutrition is the essence of what the body needs to maintain or improve exercise performance, recovery from fatigue and injury prevention. Several nutrition which had been investigated and their effects were: 1) Caffeine could effectively improve body strength. It also could be used for recreational sport or sports which were related with resistance, 2) Supplements which contain protein, vitamin, mineral were recommended to be consumed for injury prevention and good performance, 3) Beverages which contain carbohydrate and electrolyte were able to increase or prevent the decline of performance when they were taken as fluid substitute (Hackney, K.J. et al, 2012; Higgins, J.P. et al, 2010; Jenkinson, D. M. and Harbet, A.J., 2008).

In previous study, fruit-infused water was able to elevate blood glucose approximately
45 minutes since its intake (Ali, M.A. et al, 2016). Therefore, the purpose of this study was to investigate the effects of fruit-infused water (combination of apple, banana and lemon) on body weight and urine color as the markers of dehydration caused by exercise.

\section{Methods}

This was an experimental research study. The independent variable in this study was fruit-infused water while the dependent variables were body weight and urine color as dehydration markers. It was conducted from 06:00 a.m. until 12:00 p.m.

Twenty-four young men (aged 1920 years) were divided into three groups, 1) fasting-exercise-only (FEO), 2) fastingexercise-water (FEW), and 3) fasting-exercisefruit-infused water (FEF). The following procedure was implemented: 1) Subjects were examined a week before the experiment. 2) Informed consent was obtained from each subject. 3) One day before the experiment, all subjects received instructions regarding the study protocol ( $12 \mathrm{~h}$ fasting from food). 4) On the day of the experiment, the subjects were asked to sit and rest for 15 minutes. 5) Two hours before exercise, the treatment drink were administrated: $500 \mathrm{~mL}$ of either water or fruit-infused water. 6) Urine collection and body weight measurement (pre-exercise data) were then taken less than 5 minutes before exercise begun. 7) The exercise was then given.

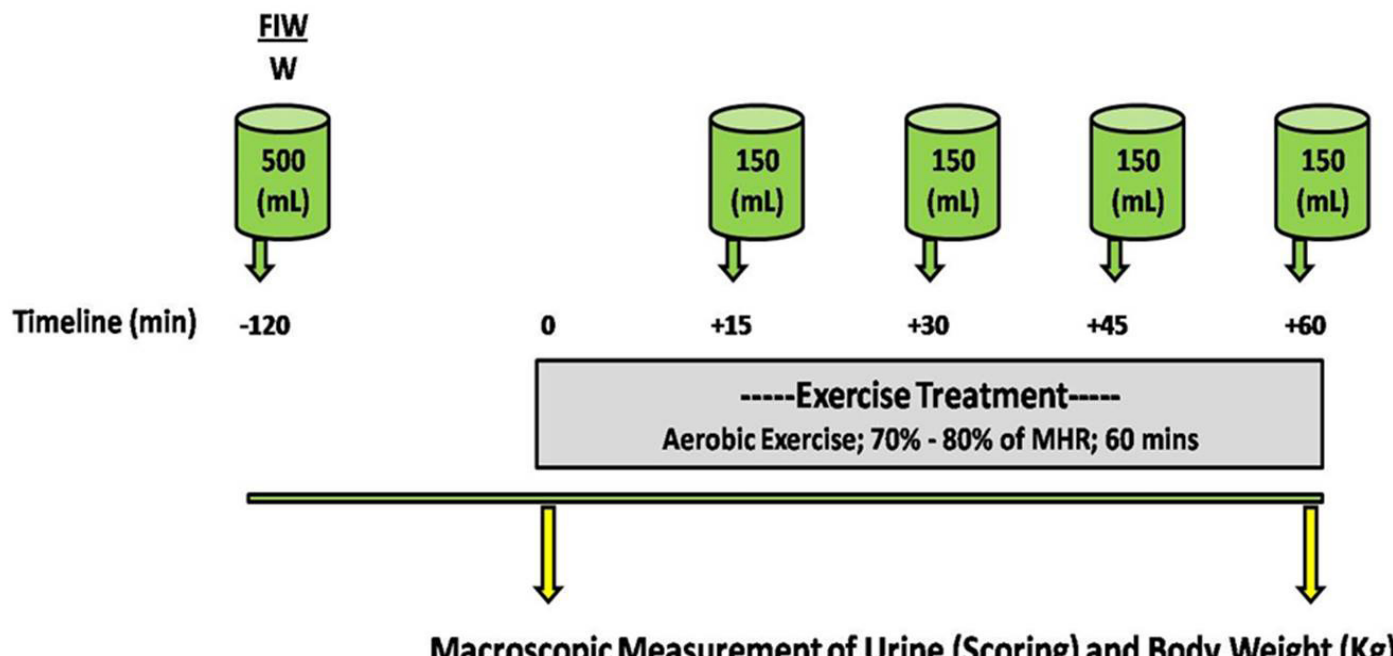

Figure 1. Study Design 
8) The administration of treatment drink: $150 \mathrm{~mL}$ of either water or fruit-infused water during exercise every 15 minutes until $1 \mathrm{~h}$ had elapsed. 9) The second collection of urine and measurement of body weight (post-exercise data) were performed immediately after exercised had finished. The study procedures were approved by the Institutional Human Study Committee of Faculty of Sports Sciences, Semarang State University (Universitas Negeri Semarang).

Fruit-infused water, which contained 212 $\mathrm{Kcal} / \mathrm{L}$ of energy, was obtained from $138 \mathrm{~g}$ of apple, $118 \mathrm{~g}$ of banana and $108 \mathrm{~g}$ of lemon. This recipe also contained $61 \mathrm{~g} / \mathrm{L}$ of carbohydrates which is equal to $6 \%$ of a carbohydrate beverage (recommended for sport drink). Mineral water was used in this recipe. The following procedure was followed for the fruit-infused water: 1) The apple and lemon were washed. The banana was peeled and thinly sliced. 2) The fruits were mixed, (the juice and flavor ere extracted from the fruits by pressing and twisting them with a mixer in batches before and after adding the liquid). Mixed fruit adds flavor quickly. 3) The fruits were then crushed and the herbs were pressed with a flavor wand to release their flavors. The fruits were crushed gently because over-crushing could cause bitter taste. 4) Instant infusion was then performed. This process involves combining liquid with mixed fruits and crushed herbs and pumping the beverage with a flavor wand. The wand was held vertically while pumping it up and down. The bottle/container was then closed and placed in the refrigerator for a minimum of 30 min until the temperature reached $15-22^{\circ} \mathrm{C}$. At this point it was ready to be drink (Ali, M.A. et al, 2016).

The exercise was designed based on FITT formula with some modifications. It consisted of running for 60 minutes with intensity of $70 \%-80 \%$ of Maximum Heart Rate (MHR) on treadmill with $3^{0}$ incline. Target intensity was monitored using indicators of: 1) awareness that breathing is harder, and 2) ability to talk but difficult to hold the conversation. In addition, the subjects were asked to wear sauna jacket during exercise in order to increase their body temperature and sweating (Murray, B., 2007).

Body-Weight Scale Type ZT-120 was used in this study. The subject step on it barefoot and wearing underwear. The specifications of Body-Weight Scale Type ZT-120 were: 1) Maximum weight which can be measured: 120 kg. 2) Height range: 70-190 cm. 3) Method of measurement: Automatic. 4) Accuracy: $0.1 \mathrm{mg}$. The steps of urine collection were: 1) Collection of urine for about $2 / 3$ of glass tube. 2) The color was then observed and matched with color in the urine chart, converted into number to determine the dehydration level (Simpson, M.R. and Howard, T., 2011).

The data were expressed as the means \pm standard errors of the mean (SEMs). The t-test was used to determine whether there were any effects of fruit-infused water on body weight and urine color. A level of $P 0.05$ was considered statistically significant.

\section{Results and Discussion}

Each of the experimental groups consisted of 8 subjects. The average ages of all subjects were 19 years old. The maximum heart rate of all subjects was $200 \mathrm{bpm}$, and 70 percent of the target heart rate (THR) was $140 \mathrm{bpm}$, while 80 percent of THR was $160 \mathrm{bpm}$.

The Body Weight $(\mathrm{Kg})$, in all experimental groups were decreased by $1 \%$ during endurance exercise (FEO: -880 g; FEW: -560 g; FEF: -790 g), (Table 2). The treatment drinks, either water (FEW) or fruit-infused water (FEF), could not prevent the $1 \%$ loss of body weight compared with control group (FEO) $(P>.05)$.

One percent decrease in body weight during endurance exercise might lead to reduced performance. However it was not enough to impair the performance because loss of $2 \%$ in body weight caused performance impairment for about 7\% - 29\% (Goulet, E.D.B., 2012). Loss of body weight which occurred in this study was classified as modest/mild dehydration, which was commonly found in team-sport (Osterberg, K.L. et al, 2009). Moreover, previous studies confirmed that loss of $1 \%$ to $2 \%$ of body weight caused adverse effects on physiological function and muscular endurance which was correlated with change in cardiac output, and negatively affect performance, but the muscle strength was relatively unaffected (Goulet, E.D.B., 2012; Cengiz, A. and Demirhan, B., 2013).

$1 \%$ to $2 \%$ loss of body weight could impair cognitive function, led to reduction 
Table 1. Characteristics of Subjects

\begin{tabular}{|c|c|c|c|c|c|}
\hline \multirow{2}{*}{$\begin{array}{c}\text { Experimental } \\
\text { Groups }\end{array}$} & \multirow{2}{*}{$\mathbf{n}$} & \multirow{2}{*}{ Age (years) } & \multirow{2}{*}{$\begin{array}{l}\text { Maximum } \\
\text { Heart Rate } \\
\text { (bpm) }\end{array}$} & \multicolumn{2}{|c|}{ Target Heart Rate (bpm) } \\
\hline & & & & $70 \%$ & $80 \%$ \\
\hline FEO & 8 & 19,75 & 200,25 & 140,18 & 160,20 \\
\hline FEW & 8 & 19,38 & 200,63 & 140,44 & 260,50 \\
\hline FEF & 8 & 19,25 & 200,75 & 140,53 & 260,60 \\
\hline
\end{tabular}

Table 2. Change in Body Weight (Kg) after Exercise

\begin{tabular}{ccccc}
\hline \multirow{2}{*}{$\begin{array}{c}\text { Experimental } \\
\text { Groups }\end{array}$} & \multicolumn{4}{c}{ Body Weight (Kg) } \\
\cline { 2 - 5 } & Pre-Exercise & Post-Exercise & BW Change & \multirow{4}{*}{$\Delta \%$} \\
\hline FEO & 63,31 & 62,44 & $-0,88$ & 0,001 \\
\hline FEW & 57,94 & 57,38 & $-0,56$ & 0,001 \\
\hline FEF & 65,60 & 64,81 & $-0,79$ & 0,001 \\
\hline
\end{tabular}

in subjective perception of alertness and ability to concentrate and increase in selfreported tiredness and headache. In addition, it also caused negative psychological effects on performance such as increased fatigue, anger, anxiety, decrease in mood and motivation, and increased confusion (Cengiz, A. and Demirhan, B., 2013).

Besides body weight, urine color also could be used to investigate whether individual was dehydrated or not (Simpson, M.R. and Howard, T., 2011). The change in urine color was clearly different between pre-exercise with post-exercise data $(P<0.05)$. Before exercise treatment were given, subjects from all experimental groups were in good hydrated status as the urine score in each group were
2.63 in FEO group, 3.00 in FEW group, and 2.25 in FEF group. After exercise treatment, the darkest urine color was observed in FEO group (4.75), followed by FEW group (4.25) which were classified into dehydration. Interestingly, the change of urine color in FEF group (3.63) did not reached dehydration level (Figure 2).

Exercise-induced dehydration was observed. The loss of body weight led to decrease in total body water, extracellular water, blood volume and plasma volume (Relic, D. et al, 2013). Dehydration during exercise is primarily caused by the process of evaporation (one mechanism of heat dissipation). Once the temperature is increased, the sweat gland helps the body to stabilize the core temperature. Sweating caused loss of valuable fluids from 


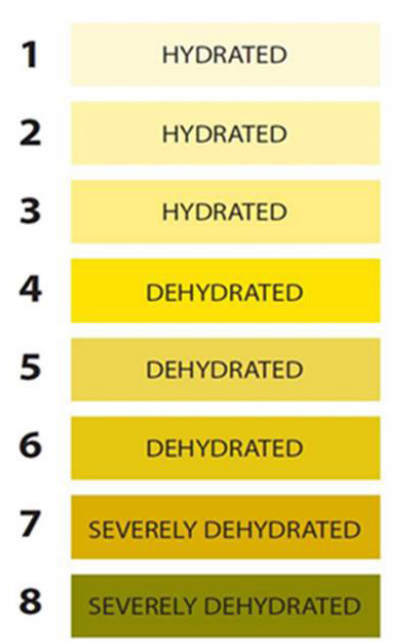

(A)

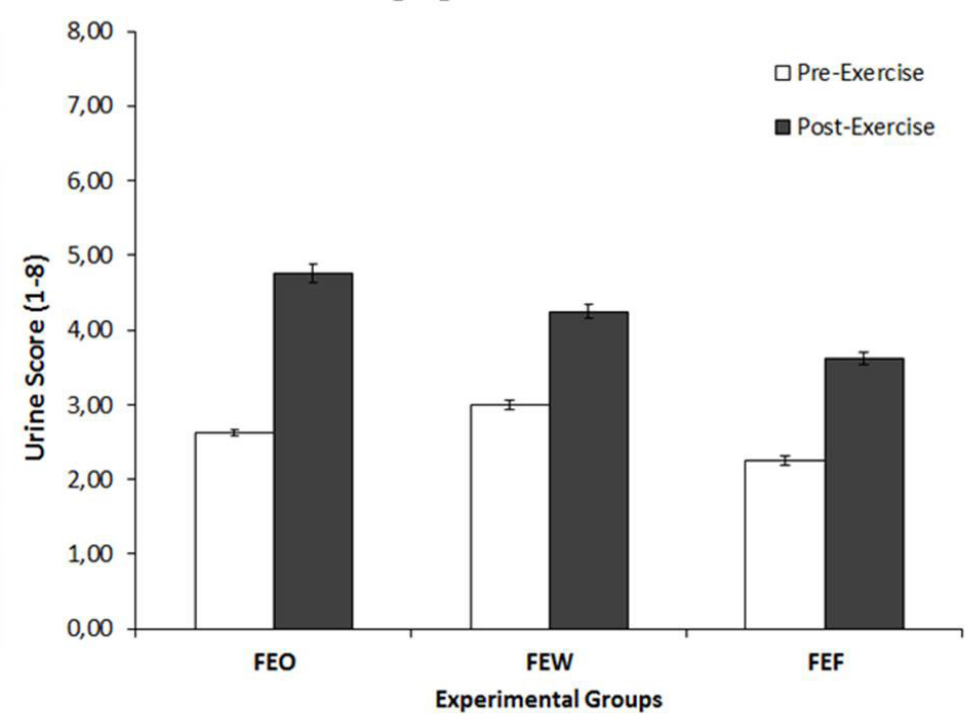

(B)

Figure 2. A. Urine Chart (Adopted from Simpson, M.R. and Howard, T., 2011), and B. Change in Urine Color after Exercise

the body. The rate is dependent to individual differences, intensity of exercise, conditions of environment, clothing, acclimatization state, and hydration status. Individual with excess sweat who undertakes intense exercise can become dehydrated. Modest dehydration carries few risks and can usually be treated by replacement of lost salts and fluids. Basically, drinking water as an effort to prevent dehydration is better than nothing. But drinking formulated liquid which content substances which are appropriate for physiological function is expected to be better.

Investigation about the usage of juice and juice-like water (fruit infused water) on health or athlete's performance had been conducted (Ali, M.A. et al, 2016; Januardi R. I., 2017). In the study which was conducted by Januardi about the effectiveness of fruit juice consumption as pain reliever for bruise trauma in pencak silat athletes, he discovered that the fruit juice was effective to reduce muscle pain. Furthermore, jamu cekok (Javanese herbal) also had been studied regarding its stimulatory effect on increasing the appetite and weight of toddler, especially the usage of Curcuma aeroginosa, Curcuma xanthorriza robx, Kaempferla galanga L, Meniran phyllanthus niruri, Zingiber americans, Carica papaya l, Curcuma domestica val, bitter and rotten tempeh (Marni \& Retno
Ambarwati, 2015).

Endurance exercise in this study successfully caused dehydration by decrease of $1 \%$ of body weight. Unfortunately, the intake fluid either water or fruit-infused water could not prevent the loss of body weight. Furthermore, the change of urine color was suppressed only by drinking fruit-infused water. Fruit-infused water is suggested to be drink as a choice for fluid intake during endurance exercise.

\section{Conclusion}

Body weight in all experimental groups were decreased by $1 \%$ during endurance exercise. This loss could not be prevented either using fruit-infused water or water compared with FEO group $(p>.05)$. The change in urine color was clearly different between pre-exercise and post-exercise data $(p<.05)$. The darkest urine color was observed in FEO group (4.75), followed by FEW group (4.25), while FEF group (3.63) did not reached dehydration level. Fruit-infused water is suggested to be drink as a choice for fluid intake during exercise.

\section{Acknowledgements}

The authors would like to express gratitude to the Faculty of Sports Sciences, Universitas Negeri Semarang for the grant, therefore this study could be successfully conducted. The authors also would like to say 
thank you to all volunteers that gave much supports to this study.

\section{References}

Ali, M.A., Mukarromah, S.B., Anggita, G.M., Suraya, F., Anam, K. 2016. The Effect of Fruit-Infused Water (Combination of Apple, Banana and Lemon) on Blood Glucose in Young Men. Pakistan Journal of Nutrition, 15(7): 693-695.

Cengiz, A. \& Demirhan, B. 2013. Physiology of Wrestlers' Dehydration. Turkish Journal of Sport and Exercise, 15(2): 1-10.

Goulet, E.D.B. 2012. Effect of Exercise-induced Dehydration on Endurance Performance: Evaluating The Impact of Exercise Protocols on Outcomes Using A Meta-analytic Procedure. British Journal of Sports Medicine, 47(11): 679-686.

Hackney, K.J., Cook, C.B., Fairchild, T.J., PloutzSnyder, L.L. 2012. Skeletal Muscle Volume Following Dehydration Induced by Exercise in Heat. Extreme Physiology \& Medicine, 1(3).

Hagen, K.B., Dagfinrud, H., Moe, R.H., Osteras, N., Kjeken, I., Grotle, M., Smedslud, G. 2012. Exercise Therapy for Bone and Muscle Health: An Overview of Systematic Reviews. BMC Medicine, 10(167): 1741-7015.

Higgins, J.P., Tuttle, T.D., Higgins, C.L. 2010. Energy Beverages: Content and Safety. Mayo Clinic Proceedings, 85(11): 1033-1041.

Januardi Roy Irawan. 2017. The Effectiveness of Passion Fruit Juice Consumption as Pain Reliever for Bruise Trauma in Pencak Silat Athletes. Jurnal Kesehatan Masyarakat, 12(2): 96-101.

Jenkinson, D. M., Harbert, A. J. 2008. Supplements and Sports. The American Family Physican, (www.aafp.org./afp).

Locks, R.R., Costa, T.C., Koppe, S., Yamaguti, A.M., Garcia, M.C., Gomes, A.R.S. 2012. Effects of Strength and Flexibility Training on Functional Performance of Healthy Older People. Revista Brasileira de Fisioterapia, 16(3): 184-190.

Marni \& Retno Ambarwati. 2015. Khasiat Jamu Cekok Terhadap Peningkatan Berat Badan pada Anak. Jurnal Kesehatan Masyarakat, 11(1): 102-111.

Murray, B. 2007. Hydration and Physical Performance. Journal of the American College of Nutrition, 26(5): 542S-548S.

Osterberg, K.L., Horswill, C.A., Baker, L.B. (2009). Pregame Urine Specific Gravity and Fluid Intake by National Basketball Association Players During Competition. Journal of Athletic Training, 44(1): 53-57.

Relic, D., Hassler, E., Jost, J., Friedmann-Bette, B. 2013. Rapid Weight Loss and the Body Fluid Balance and Hemoglobin Mass of Elite Amateur Boxers. Journal of Athletic Training, 48(1): 109-117.

Sawka, M. N., Burke, L. M., Eichner, E. R., Maughan, R. J., Montain, S. J., Stachenfeld, N. S. 2007. Exercise and Fluid Replacement. Journal of the American College of Sports Medicine, 20(10): 377-390.

Simpson, M. R. and Howard, T. 2011. Selecting and Effectively Using Hydration for Fitness. American College of Sports Medicine Consumer Information Committee. 